\title{
Un mundo sin certezas: la polis, el Estado-Nación y el orden internacional
}

\author{
A world without certainties: the polis, the Nation- \\ State and the international order
}

\author{
Juan Archibaldo Lanús ${ }^{1}$
}

El historiador inglés Eric Hobsbawn, en el libro La Era del Capital, ha dicho lo siguiente sobre el tiempo que vivimos: "en la mitad del siglo pasado hemos ingresado en una nueva fase de la historia mundial. Es el fin de una historia, la que hemos conocido en los diez mil años pasados, es decir, desde la invención de la agricultura sedentaria. No sabemos hacia dónde vamos".

Según Hobsbawn se trata del "fin de una historia" y no del "fin de la historia", como algunos intelectuales lo creyeron después de la caída del Muro de Berlín, cuando el mundo occidental se vanagloriaba del triunfo definitivo de la economía de mercado y la democracia, mientras se derrumbaba la utopía comunista. El gran historiador alentaba: "no sabemos a dónde vamos", vivimos una época imprevisible.

En estas reflexiones me referiré a lo que está ocurriendo en tres tableros de la política: la polis, el Estado-Nación y el orden internacional.

La democracia como forma de gobierno, consiste en la autogestión de los intereses colectivos de una sociedad, asentada en un territorio, con el objetivo de realizar el bien común. En la actualidad este propósito está puesto en duda por una tensión cada vez más visible entre la democracia que tiene lugar en un espacio territorial y los intereses de una tecnoestructura globalizada no territorial que está gerenciada en función de intereses económicos particulares. Estos intereses, que no dependen de ninguna soberanía estatal, ejercen una influencia decisiva sobre los gobiernos de los países democráticos, intentando

DOI: $10.24215 / 23142766 \mathrm{e} 099$

${ }^{1}$ Docteur es lettres por la Universidad de la Sorbona, Paris, Francia. Secretario de Estado de Relaciones Exteriores (1989) y Embajador en Francia (1994-2000 y 2002-2006) y ante la UNESCO (2002-2003). 
influir o dominar las élites, mientras que las opiniones públicas establecen complicidades que favorecen sus intereses globales. En un caso se trata de "gobernar a seres humanos"y en el otro se administran cosas. David Goodhart en su obra, The road to Somewhere, identificaba dos tipos humanos que responden a paradigmas opuestos: personas de Anywhere (de cualquier parte) que valoran la autonomía, la movilidad y están menos ligadas a la tradición e identidades nacionales; y, en el otro extremo, las personas que él llama de Somewhere (de algún lado), que están arraigadas, conservan la ética tradicional y están menos preparadas para el cambio y la movilidad. En un caso estamos frente a un cuerpo político con una historia nacional, en otro ante una acumulación de activos administrados según intereses económicos de los accionistas.

Si observamos atentamente la energía e imaginación que despliegan los gobiernos, nos percataremos de que gran parte está enfocada hacia la tensión y conflictos entre ambos universos. Los gobiernos están más atentos a lo que opina o espera el presidente de un Fondo de Inversión o de una calificadora de riesgo país sita en Luxemburgo o Nueva York, que a la opinión o deseo del trabajador rural de Anguleme en Francia. Gran parte de las críticas que se hacen a la Comisión Europea de Bruselas -que tiene acreditados más de diez mil lobistas- es por ocuparse con mayor dedicación a conformar los intereses u opiniones de la tecnoestructura globalizada que las demandas o expectativas del ciudadano común. ¿No será que los grandes conflictos de las sociedades modernas y desarrolladas son entre la gente de "anywhere" y la de "somewhere"?

Cada vez más la gestión gubernamental se centra en cosas, reflejadas en cifras e índices y no en temas de la vida de las familias, sus placeres, sus esperanzas. El peligro que acecha la democracia ya fue imaginado en la obra futurista 1984 de George Orwell, donde el Estado ejerce un control permanente de la persona. El "gran hermano" es una figura fantasmagórica que todo lo sabe, todo lo vé. Aldous Huxley también a mediados del siglo XX, en su novela de ficción Un Mundo Feliz, planteaba los peores vaticinios de una sociedad dominada por el consumo, donde el poder se organiza para manipular la voluntad del ciudadano a fin de que responda a los intereses de las minorías. En esa sombría metáfora, los seres humanos son reproducidos in vitro, sacrificándose los valores esenciales del hombre.

Actualmente para asegurar esa dominación a los grupos políticos, se ofrecen los servicios de empresas que manejan las BIG Data, como: Oxford Facilities, y otras que acumulando infinidad de informaciones sobre las personas llegan a controlar sus consumos o entretenimientos e intentar condicionar su voto. En Europa hay varios procesos por la manipulación de elecciones, por parte de poderes extranacionales. Orwell ya había previsto en su novela la creación de un "Ministerio de la Verdad", cualquier similitud con la Argentina es mera coincidencia... He aquí una de las grandes amenazas a la democracia.

El mundo de la democracia está en peligro, porque el sueño colectivo que propone la gestión del bien común está siendo sustituido por la administración de las cosas y por el individualismo. Los poderes políticos están desertando la finalidad de estar al servicio de las apetencias esenciales del ser humano, la felicidad o la justicia, porque solamente juzgan su gestión en función del éxito económico.

En conclusión, se está abandonando la preocupación por la virtud de "gobernar a seres humanos", en un camino hacia la técnica de la "administración de las cosas". 
El nuevo proceso de la globalización iniciado con la apertura de la Bolsa de Londres en la década del ochenta del siglo pasado y las sucesivas liberalizaciones monetarias ha erosionado las bases del Estado-Nación, y su concepto de soberanía tiene características distintas de las dos anteriores. El impulso hacia la globalización lo lideran los actores privados, individuos y empresas, apoyados en el soporte de una revolución tecnológica en materia de comunicaciones.

A diferencia del soporte tecnológico del proceso actual, la globalización de la Belle Epoque que se inaugura con la supresión de las Corn Laws de Gran Bretaña en 1846 y se extiende hasta la primera Guerra Mundial, se llevó a cabo a través del mercado por un acelerado aumento del flujo transnacional de bienes, servicios inversiones y migraciones. Era un mundo donde se podía transitar sin obstáculos y está caracterizado por el personaje de Julio Verne, quien en su novela la Vuelta al mundo en 80 días, viaja por el mundo y atraviesa fronteras solo presentando su carta de visita.

La IGM echó por tierra las bases del proceso de globalización y la historia ha transformado el crack de la Bolsa de Nueva York de octubre de 1929 en un hito divisorio de aguas. Luego viene la época del proteccionismo (La ley Aduanera Smott Hawley de los EE.UU. es emblemática) y el intervencionismo del Estado en la economía.

Los inventos que posibilitaron esta nueva era que alguien llamo de la "conectividad" son la Internet (creada por Vinton Cerf y Robert Kahn) y la World Wide Web, espacio abstracto de información (inventado por Tim Berners Lee).

La revolución en la tecnología de las comunicaciones ha jugado un rol central en la configuración de esta nueva globalización: las computadoras se han transformado en una fuerza pluralizadora que fomenta la formación de un mercado libre más que la centralización del poder. La novedad de la numerización, especie de ADN de la información, que permite codificar y descodificar cualquier secuencia de ceros y de unos, es lo que equivale para Nicolás Negroponte, autor de El Hombre Numerico- a una transformación de átomos en electrones. El byte es el nuevo universo del lenguaje planetario, cuyo viaje es casi indetectable y no cuesta prácticamente nada.

El tiempo ha vencido al espacio y la comunicación ha abolido el peso de la geografía. Este proceso de globalización ha socavado las realidades que suponía el Estado-Nación, un estado sostenido por el principio de la soberanía, según la concepción del Tratado de Westfalia de 1648, y la idea de frontera, que identificaba en el espacio el límite de una comunidad (en el imperio romano, llamado limes). Ese adentro y afuera ha sido relativizado por la intensificación de flujos transnacionales y porque las materias abarcadas por el derecho internacional penetran los espacios nacionales.

Asistimos ahora a la finalización del orden de Westfalia que consagró lo que algunos designan como la concepción "Estado deísta”, cuya última expresión es el Estado-Providencia.

El Estado ha dejado de ser el único centro de poder. En razón de los imperativos de la actividad económica, este debe hoy limitar el peso fiscal de su costo social para adaptarse a una competición regional y global. Más aun, las conductas de los Estados son evaluadas por 
los mercados y por los ciudadanos. Calificadoras privadas establecen índices que evalúan las conductas y políticas de los gobiernos (Transparency establece índices de corrupción y Unwatch determinasi cumple con las normas de la ONU). Existen calificadoras de conducta ecológica, del cumplimiento de derechos humanos, de libertad de prensa, etc. Por otra parte, las negociaciones diplomáticas cubren temas que estaban reservados, desde hace 30 años, al dominio interior exclusivo y, salvo en las sociedades llamadas primitivas o muy reducidas, la sociedad civil juega un papel nunca imaginado.

Algunos, como Kenichi Ohmae en Globalisation and Regionalism. The challenge for Developing Countries, denominan a la nueva situación del Estado "Estado post Nacional". Otros autores utilizan el término "Postsoberano". Hay quienes afirman que la única verdadera soberanía que conserva el Estado es la externa. Jean-Marie Gueheno hace más de una década hablo del "Fin del Estado-Nación" (La fin de la démocratie). En general presenciamos lo que John Gray, profesor de política en la Universidad de Oxford, en su libro Falso Amanecer, afirma que hay: "un derrame de poder" que afecta tanto a los Estados como a las grandes corporaciones. Los Estados no desaparecerán, pero tendrán otra función de mediación.

Este proceso de integración de los mercados nacionales asegurados por cientos de miles de operadores ligados por computadoras fue completado, a fines del siglo pasado, por una gran movilidad de flujos financieros (que representan más de cien veces el valor del comercio mundial) y una gran facilidad para trasladar procesos productivos a distintos lugares del planeta, lo que denomina la "deslocalización".

Como consecuencia, los Estados ya no deciden ni pueden decidir poco sobre el valor de sus monedas, y forman un enorme mercado de colocaciones manejado por inversores institucionales (fondos de pensión, fondos comunes y compañías de seguros) que escapan al control estatal.

Esta situación ha creado una nueva relación entre el Estado, cuya razón de ser es la justicia, y el mercado, que tiene por función la mejor distribución de los recursos. Jacques Attali afirmó que existe el riesgo de que: "el mercado termine por privatizar el conjunto de las funciones del Estado y que progresivamente nos encontramos no solo con la libertad de comercio sino con la privatización de la educación, la salud, la justicia y la defensa". Mientras que el mercado tiene por su naturaleza una vocación mundial, la democracia es territorial. Attaliafirma que el mercado puede transformarse un día "en el peor enemigo de los Estados que lo percibirán como una amenaza a su identidad nacional" (Entrevista a Jacques Attali y Pascal Lamy. Le Fígaro, 25 de enero de 2007).

La erosión del Estado-Nación y la pérdida del prestigio de las utopías colectivas han favorecido la emergencia del individuo y las redes sociales. Lo "publico" cede lugar a lo "privado". La autoridad de los gobiernos ha perdido terreno frente a las fuerzas del mercado, erráticas y globalizadas.

El entretenimiento lúdico, el paradigma de la riqueza y el éxito rápido difundido por las redes de comunicación mundial como paradigma de un modelo social globalizado amenazan la cultura tradicional. La dinámica consumista de este proceso sobre los modelos sociales ha legitimado el desarrollo de un "ego económico" que se impone por sobre el valor que se asignaba al conocimiento, a la política o a la tradición. El poder económico se ha transformado en un factor determinante de la consideración y respetabilidad social. En 
muchos países, el desarraigo, una cultura de aeropuerto o de casino, ha empobrecido la vida humana.

En general, se podría afirmar que la reinstalación del proceso de globalización ha derribado el paradigma del borde: el tiempo le gano al espacio... La revolución tecnológica ha instaurado, entre un gran número de habitantes del planeta, lo que podría llamarse un intimismo social.

Algunos fenómenos son, a mi juicio, claros:

La erosión del Estado-Nación y la pérdida de prestigio de las utopías colectivas han favorecido la emergencia del individuo; lo público cede su lugar a lo privado.

No es aventurado afirmar que nos hemos embarcado en una tendencia que puede borrar las fronteras de las economías nacionales, supuesto de las teorías económicas desde la época del mercantilismo.

Sin embargo, muchos piensan que se están abriendo las compuertas de un reservorio ignoto de dinamismo y crecimiento. Una nueva percepción del tiempo y del espacio amplía las fronteras de nuestra acción.

La erosión del Estado-Nación y la delimitación soberana de los espacios nacionales ofrecen un universo nuevo, cuyos efectos son imprevisibles o difíciles de pronosticar anticipadamente.

III

Luego de la caída de Napoleón, el Congreso de Viena instauró un orden que intentó reconstruir el viejo régimen de las monarquías con base en el equilibrio de poderes, que terminó, por la guerra y las rencillas, en un baño de sangre. La Sociedad de las Naciones ya había fracasado, cuando tiempo después de la II Guerra Mundial, el sistema de la Carta de San Francisco reeditó el sueño de un orden universal sobre la base de la "seguridad colectiva" para evitar que la práctica del equilibrio de poderes condujera a nuevas guerras.

El orden internacional creado en San Francisco en 1945 sancionó como normas de convivencia entre los Estados la igualdad, el respeto a la integridad territorial, la soberanía y la no injerencia en los asuntos internos de los Estados. No condenó la guerra, como lo había hecho en 1928 el Tratado Braind Kelogg, sino que sometió el uso del poder militar a una serie de procedimientos y requisitos sujetos a la autoridad del Consejo de Seguridad. En realidad, desnacionalizó el uso del poder militar salvo en caso de legítima defensa ( art. 51de la Carta de la ONU).

Fue una experiencia nueva, universal, en el sentido de que no prejuzgó sobre el sistema económico ni político interno. Fue la idea de Rooseveltde "one world", lo que posibilitó el ingreso a la ONU de la Unión Soviética y los países comunistas junto con las democracias.

En paralelo al orden político, se estableció un orden económico a través de los Acuerdos de Bretton Wood de 1943 y el GATT, que es sustitutivo del Acuerdo de La Habana de 1948 que no fue ratificado por los Estados Unidos. En el curso de las décadas que siguieron a la II Guerra Mundial se fueron creando una serie de instituciones que completaron el orden político y económico, como, por ejemplo, en materia de derechos humanos, medio 
ambiente y desarme. En 1994 los Acuerdos de Marrakech crearon la Organización Mundial de Comercio.

Esta arquitectura, que insumió millones de horas de trabajo diplomático, conformó el sistema multilateral cuyo objetivo era la convivencia pacífica y la cooperación entre los Estados, pero no funcionó o lo hizo con precariedad. Desde la crisis de Berlín, en 1947, que separó el mundo liderado por la Unión Soviética de las democracias occidentales, el Consejo de Seguridad de la ONU estuvo bloqueado hasta el fin de Guerra Fría. Las grandes potencias violaron las disposiciones de la Carta de San Francisco. Ejemplos de esto es la Guerra de Vietnam, que nunca se trató como tema de la Agenda de la ONU, como tampoco se trataron las intervenciones unilaterales estadounidenses en la República Dominicana (1965) y Panamá (1989). No se pudieron parar las intervenciones soviéticas en Hungría (1956) y Checoslovaquia (1968), ni la invasión a Afganistán, etc.

Finalizada la Guerra Fría (1989), se creyó posible volver a lo establecido en la Carta. Sin embargo, las Naciones Unidas, pilar del orden internacional, comenzó una etapa de progresiva deslegitimación política.

Se multiplicaron los conflictos raciales, religiosos y guerras intestinas, como las de Ruanda y Haití, y la guerra civil en Sudán, que no permitieron resolverse de acuerdo a lo previsto en la Carta.

b) A partir de la presidencia de Clinton, en los Estados Unidos, casi ninguna de las intervenciones tuvo la autorización del Consejo de Seguridad, por ejemplo, el bombardeo de Irak. En el Kosovo se invocó la intervención humanitaria, una visión arbitraria de la no injerencia. Clinton llegó a decir que la su política sería "multilateral si era posible, unilateral si era necesario".

c) Posteriormente ocurrió el atentado a las Torres Gemelas (2001), que provocó una ruptura de la estrategia de los Estados Unidos con los principios de la Carta de San Francisco, cuando la National Security Strategy fija una nueva doctrina el 20 septiembre 2002: la autorización de la guerra preventiva cuando los intereses de los Estados Unidos estén afectados por un peligro, una amenaza o percepción de agresión y, por otra parte, introduce la definición de la categoría de Estados fallidos (Corea del Norte, Libia, etc.), lo cual era contrario a la igualdad de tratamiento establecida en el Carta.

d) Finalmente, con motivo de la intervención en Irak en 2003, se abre por primera vez un gran debate sobre la legitimidad del sistema de seguridad colectiva.

Mientras Francia y Alemania defienden el sistema multilateral y la posición soberanista y de no intervención, en los Naciones Unidas se alzan las voces adversas. Dominique de Villepin, canciller francés, expresa: "sostenemos el imperio del derecho, la aplicación de las soluciones internacionales y la competencia del Consejo de Seguridad de la ONU", frente a los representantes de Washington, que se vanagloriaban con la proclamación del fin del sistema ONU. Mientras desde varios países europeos se sostenía que solo el Consejo podía autorizar una intervención militar, en el diario The GuardianRichard Perle, un consejero del Ministro de Defensa de los Estados Unidos decía: "gracias a Dios que esta muriendo la ONU" y Michel Glenon escribía en el Foreign Affairs de mayo-junio de 2003 "que era el fin de las Naciones Unidas". La gran experiencia internacionalista del siglo XX tuvo como propósito someter el uso de la fuerza al imperio de la ley. Este autor neoliberal afirmaba que "la suerte 
del Consejo de Seguridad está sellada, por la fuerza desproporcional que los Estados Unidos tiene frente a otros países."

Salvo durante el interregno de Barak Obama, los Estados Unidos no han modificado esa posición escéptica frente a la Carta de San Francisco. Los conflictos se fueron sucediendo y las soluciones para resolverlos se buscaron fuera de las Naciones Unidas, por vías unilaterales o de confrontación entre grandes potencias. El caso más patético es Siria, donde fuerzas militares rusas, norteamericanas y de otros países (Francia cambió de posición) se enfrentan en una intervención militar que mucho se parece a las del siglo XIX o principios del siglo XX.

La aparición de Donald Trump y su política de decisiones preventivas y unilaterales, y de desenfadado despliegue de fuerzas militares, es un golpe final a la legitimidad del sistema de seguridad colectiva que la Carta había puesto en manos del Consejo de Seguridad. El sueño de un orden mundial regido por acuerdos entre Estados se fue muriendo y actualmente podemos decir que su legitimidad está contestada por las conductas de los propios gobiernos con asiento permanente en el Consejo de Seguridad.

A pesar de que la acción del GATT fue excepcional en lo que hace a la liberalización de los intercambios (a fines de la IIGM el promedio de las tarifas era de 40\%), la Organización Mundial de Comercio (1994) permitió establecer disciplinas para todas las transacciones de bienes y servicios, a través de mecanismos de solución de diferencias que lograron resolver muchos conflictos. A partir del lanzamiento de la Rueda Doha en el 2001, empiezan a multiplicarse políticas proteccionistas y las normas técnicas restrictivas, tanto en los Estados Unidos como en la Unión Europea, no solo han hecho fracasar aquella rueda de negociaciones sino introducido una virtual paralización de aquellas negociaciones y un bloqueo a la maquinaria de la OMC.

En la declaración final del G 20 que tuvo lugar en Buenos Aires en diciembre del año 2018, se afirmó que hay que reformar la OMC pero no en qué aspecto. Los Estados Unidos aplica arbitrariamente la sección 301 de la Ley del Congreso de 1974 para aumentar sus tarifas aduaneras a los productos chinos. China hace lo mismo como retaliación a las medidas aplicadas por Washington.

Es evidente que la defensa del sistema multilateral de la ONU y la OMC es una causa que carece de convicción en las capitales de los grandes Estados con asiento permanente en el Consejo de Seguridad. Una larga historia de frustración por el bloqueo soviético o de cinismo por el doble discurso o el silencio de muchos países han colocado a los foros multilaterales a un costado de los ámbitos de decisión, que ni siquiera son el G7 ni el G20 sino que se parece más a la diplomacia del siglo XIX.

IV

He descripto en estas Reflexiones lo que, a mi juicio, son los cambios que se están produciendo en los tres planos en los que la vida social del ser humano tiene lugar: la polis, el Estado y el orden mundial. Pero esas mutaciones se dan en un contexto cultural que, en el caso de los países occidentales, está experimentando una transformación profunda. 
Todo parece indicar que se demolieron las columnas de una cultura que aseguraba creencias y logros en una evolución continua. A pesar del extraordinario avance tecnológico y la rápida creación de bienestar, me pregunto si podrá el ser humano cumplir con las aspiraciones profundas de su naturaleza, en una sociedad como la actual, cada vez más deteriorada en lo ecológico, alucinada por la dependencia de bienes efímeros, distraída por entretenimientos permanentes, donde los gobiernos han olvidado el bien común y el valor de la virtud como conducta personal; porque en estas sociedades los gobernantes están obsesionados con el poder y la fama o poseídos por la codicia. Cada vez más observamos que de lo que se trata no es de gobernar la sociedad humana sino de administrar las cosas. El hombre ha quedado en segundo plano.

Esta gran mutación tiene lugar en un contexto en el que en las sociedades más desarrolladas se promueve el relativismo cultural que rechaza la tradición de la herencia de valores, de concepciones éticas, de patrones de conductas virtuosas, negándose asimismo que el ser humano esté arraigado en la historia. Muchos filósofos, como Michel Foucault (estructuralismo) o Zygmunt Bauman (la sociedad líquida), insisten en el fin de la ética heredada, en el divorcio entre el Estado y la moral, y conciben una sociedad que vive en la precariedad, en la incertidumbre constante, donde muchos valores son descartables. No se busca lo sólido ni lo que permanece, lo que se posee, sino lo rápido, fluido, sin identidad ni raíces.

Coincidiendo con el nuevo proceso de globalización han aparecido dos fenómenos que merecen comentarse:

a. La creciente desigualdad entre personas de ingresos altos y los de menos recursos, y entre las naciones, hace impredecible las posibilidades de consolidar la paz social en el mundo.

b. Se ha expandido una sensación de "temor" frente al recurrente anuncio de acontecimientos catastróficos que amenaza alterar la naturaleza y la vida social o física de individuos y familias.

El santo Padre Francisco, el 5 de febrero de 2020, dijo que las cincuenta personas más ricas del mundo tienen un patrimonio equivalente a 2,2 billones de dólares (Discurso ante la Pontificia Academia de Ciencias Sociales, Vaticano). La desigualdad entre países también ha crecido. En 1820 el país más rico tenía un ingreso 4,5 veces mayor que el más pobre, en 1913 era 15 veces mayor y en el año 2000 la diferencia llego a 71 veces más. (World Developement Indicators 2002. World Bank)

En el interior de los países ocurre lo mismo. La región de América Latina y del Caribe registra la mayor desigualdad de ingresos del mundo. El $10 \%$ más rico concentra el $37 \%$ de los ingresos y el $40 \%$ más pobre recibe el $13 \%$. En el año 2015 el $28 \%$ de los latinoamericanos eran pobres, porcentaje que se elevó al 31\% en 2018. Este es un nuevo desafío para todos los gobernantes que, de no resolverse a partir de cauces para una mejor distribución del bienestar, provocará impredecibles enfrentamientos entre grupos sociales y entre naciones.

La revolución de las comunicaciones informáticas ha incentivado un aumento masivo de informaciones y mensajes, sobre todo a través de la televisión y entre poseedores de teléfonos móviles. Una saturación de noticias y datos, gran cantidad de los cuales transmiten malas o inquietantes informaciones, produce en la psiquis de millones de personas un "temor" larvado ante posibles acontecimientos que amenacen su vida física o social: hechos, 
amenazas o peligros reales o ficticios se suceden de continuo, fragilizando la seguridad de los individuos y sus familias. Intervenciones militares ( Kosovo, Irak, Siria, etc.), amenazas al medio ambiente (incumplimiento de los Acuerdos de Paris, disminución del nivel de los océanos, expansión del agujero de la capa de ozono, etc.), ataques ecológicos (incendios en la Amazonia y en Indonesia, polución en las grandes ciudades), pestes y enfermedades nuevas (gripe aviar , Sida), infecciones como el ébola o cólera, así como anuncios de que algunos países están preparando virus artificiales para iniciar lo que imprudentemente se anuncia como guerra biológica, y otras amenazas a la salud humana (Bill Gates, el creador de Microsoft, anunció en una conferencia en la Universidad de California que un virus que matará millones de seres humano).

Desde la niñez, el temor de agresiones, accidentes o desastres naturaleza están sustentados en frecuentes películas comerciales con zombis y personajes que suscitan miedo, no con la inocencia de los antiguos cuentos de niños sino con la frialdad de un juego de poder y aniquilación.

La aparición del coronavirus abrirá un nuevo capitulo en la historia de los hechos sociales por haber despertado, en algunos casos, un verdadero pánico frente a una enfermedad no más grave ni letal que una gripe.

Es la primera vez que se percibe el contagio de una enfermedad como una amenaza global, que ha provocado la introducción de respuestas parecidas en la mayoría de los gobiernos, muchos de los cuales sintieron amenazada su legitimidad.

El hombre ha convivido con virus, bacterias y hongos desde la antigüedad. Se registran tétricos recuerdos que costaron la vida a millones de seres humanos: Tucídides habla de la peste de las Guerras del Peloponeso que mató a Pericles; la peste de la época de los Antoninos mató a miles en Roma, entre ellos al emperador Marco Aurelio; la del Medioevo se llevó un tercio de la población europea. Magallanes murió antes de finalizar su viaje alrededor del mundo. La fiebre amarilla asoló a barrios enteros de Buenos Aires en el siglo XIX. Tampoco podemos olvidar la terrible gripe española, que mató a más de 20 millones de seres humanos. Aquellas pestes, más letales que el Coronavirus, no tuvieron las consecuencias políticas, sociales, económicas y culturales que tendrá la pandemia desatada a principios del 2020. Ha sucedido algo distinto en esa dialéctica entre la salud humana y la enfermedad.

Creo que dos factores fueron las causas de lo que denomino un "pánico pandémico", aun cuando la realidad es asombrosa y sus orígenes poco claros.

Dos factores podrían ser los desencadenantes de la situación. Una noticia falsa que hizo circular el Informe del director del Imperial College of London, Neil Ferguson, en la que anunciaba cuarenta millones de muertos y, por otro lado, la denuncia del Gobierno de Washington de que se trataba de un "ataque" proveniente de China. Por el anuncio de marzo, el pánico se apoderó del mundo en esta época en la que el estado físico y la juventud son los bienes más preciados para las masas de consumidores y, por otro, el anuncio de que China había desatado un "ataque con un virus desconocido" puso en alerta la seguridad de muchos gobiernos, que se sintieron responsables de la vida de sus pueblos luego de tanto oír que un monstruo intentaba dominar el mundo... Ambos miedos se juntaron en respuestas improvisadas. los sistemas de salud no estaban preparados para enfrentar ese 
tipo de pandemia, como lo declararon muy al principio -en medio de una gran confusión en donde los expertos se contradecían y las informaciones de que se trataba de "una conspiración" partieron hacia los cuatro vientos del planeta. Si bien la cuarentena nunca fue recomendada por la OMS, parecía ser la medida más impactante y fácil para mostrar autoridad, mientras se preparaba una caótica respuesta sanitaria. (Se metieron en el mismo corral sano y enfermo.)

La realidad, a mi criterio, es la siguiente: La noticia del Imperial College era infundada, la denuncia de un ataque del virus era una manifestación de la paranoia norteamericana, la gravedad del efecto del "virus" sobre la salud humana no era mayor que los efectos de una gripe (aunque quizás más contagioso), y la estrategia de magnificar o reducir el peligro que adoptaron algunos gobiernos fue eficaz para profundizar la sensación de miedo -p.e. al contar las muertes todos los días- entre las poblaciones, que, sin conocimiento de la situación, se sometieron a las autoridades abandonando sus derechos y aún aceptando que no hubiera debate entre expertos e intelectuales sobre la realidad que se vive en los primeros seis meses desde que apareció la noticia de la existencia del virus (natural o artificial).

Nadie tuvo la prudencia de esperar a tener un poco más de información antes de sentenciar el peligro, como enseñó Prometeo, quien escondió la prognosis (Elpis) en la Caja de Pandora. Miles de artículos y opiniones parecen haber agregado un poco más de irracionalidad a lo que es ya un fenómeno social que tendrá graves consecuencias para la humanidad, pero también agregará confusión en la gran tarea de descifrar ese misterio que encierra la extraña dialéctica entre la salud y la enfermedad del ser humano. El virus confirma la incertidumbre.

¿Es posible afirmar entonces que, en el contexto actual, el ciudadano es dueño de su destino y forma parte de esa entidad soberana que se llama pueblo? ¿Qué espacio tiene la libertad del hombre para realizar su destino personal y colectivo en el contexto de la polis y del mundo actual?

Las grades corrientes del pensamiento tradicional, como las de Aristóteles, San Agustín, Santo Tomás Locke, y todos los pensadores posteriores estuvieron de acuerdo en que el objetivo del gobierno de una sociedad es el bien común, y el de las personas debe de ser guiado por la virtud.

Tenemos la imperiosa necesidad de asegurar a la persona, la libertad, el bienestar y una educación de calidad, sin la cual le es imposible al ser humano participar como actor en el marco de las instituciones democráticas y menos aún en el proceso productivo.

El orden mundial creado en San Francisco se está resquebrajando, no por una división de bloques sino por la negación de algunas grandes potencias a aceptar compromisos multilaterales en materia de reglas de conducta, en lo político, en lo económico, en lo ecológico o en materia de desarme. Pareciera que la visión de Hobbes y Maquiaveloha triunfado sobre la visión aristotélica, cristiana y kantiana. A esa tendencia se suma el hecho de que los hombres no han podido desactivar la maquinaria bélica ni, lo que es peor, la fábrica ya instalada de guerras futuras. El Observatorio sobre Conflictos Internacionales de UPSALA (Suecia) confecciona un índice Global de Paz que señala que los conflictos han aumentado. 
Cuando fui presidente del Comité Internacional del Alto Comisionado para Refugiados de la ONU, nos escandalizaba el hecho de que, en aquel momento, 1993, había 17 millones de refugiados. Más de dos décadas despues hay más de 60 millones de refugiados.

Hoy, después de más de 70 años de aquel excepcional paso que consistió en la creación de un nuevo sistema internacional, estamos retrocediendo de tal modo que nuestro Papa Francisco se ha visto obligado a alertarnos sobre el riesgo de una posible confrontación global así como de los peligros de la degradación de la vida sobre la Tierra. "Fácil es el descenso al infierno", decía Virgilio.

Se ha desatado una nueva competencia entre grandes potencias, estimuladas por el poder y orgullo entre los gobernantes. Hay un estudio producido en el Belfer Center dela Universidad de Harvard, que afirma que cuando una potencia emergente desafía a una potencia dominante, la situación lleva a la guerra. Se llama la Trampa de Tucídides. Este fenómeno de que la competencia termina en guerra fue comprobado en 12 de los 16 casos analizados. Entre 1980 y 2017 los Estados Unidos multiplicaron su PBI 7 veces; en China el aumento fue 76 veces.

Sabemos, por convicción profunda, que el propósito de nuestras vidas es ser felices y que ello no podrá lograrse sin transitar el camino de la virtud. Pero solo la política puede garantizar la libertad necesaria para hacer estas metas posibles.

Quizás una nueva utopía salvará la historia. Como aquella que imaginó Gabriel García Márquez al recibir el Premio Nobel de Literatura: “Una nueva y arrasadora utopía de la vida, donde nadie pueda decidir sobre otros hasta la forma de morir, donde de veras sea cierto el amor y sea posible la felicidad y donde las estirpes condenadas a cien años de soledad tengan por fin y para siempre una segundaoportunidad sobre la Tierra". 


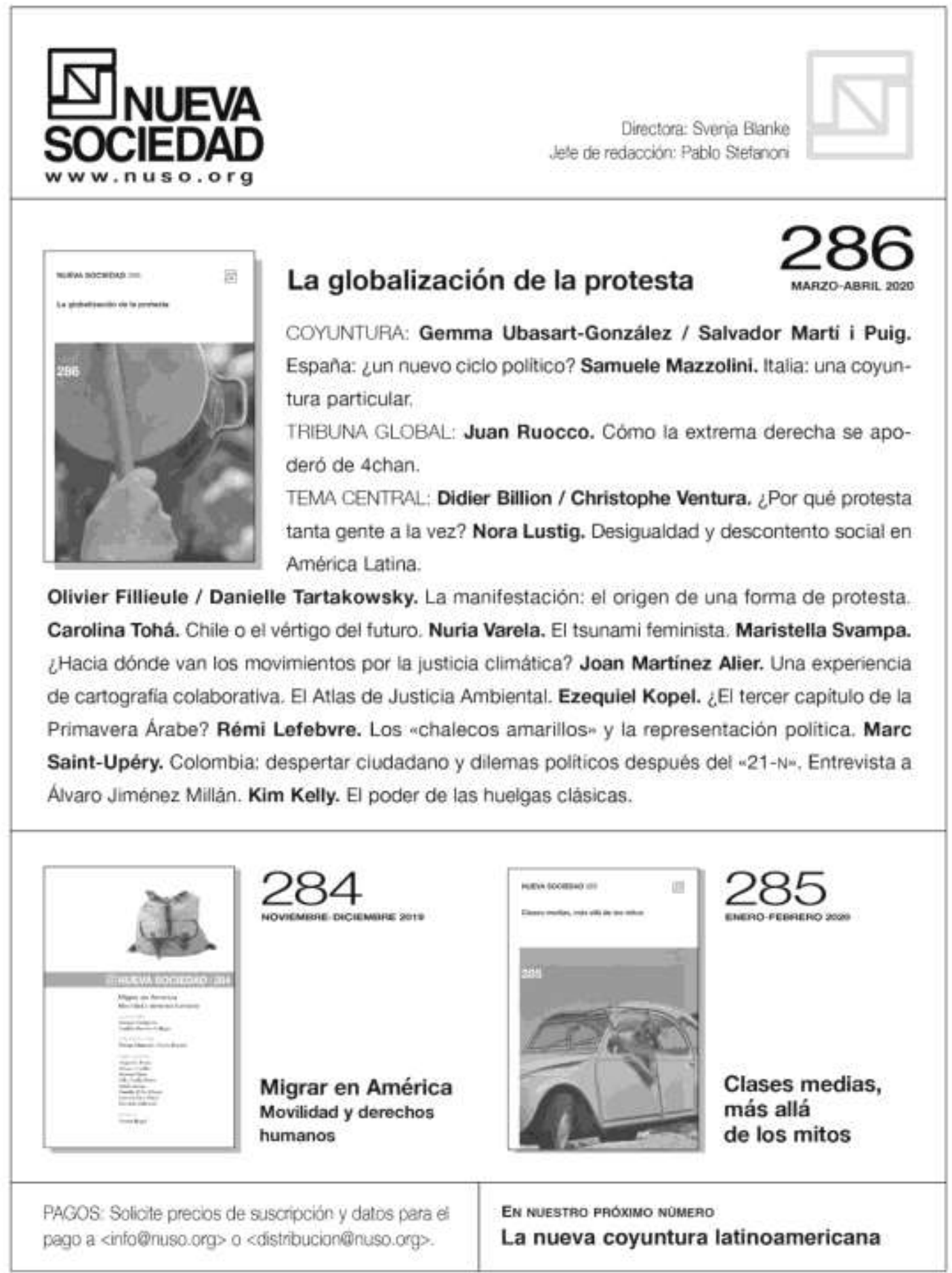

